\title{
Prediction of octane numbers of substituted alkanes according to the topological characteristics of the molecules
}

\author{
(C) Mikhail Yu. Dolomatov, ${ }^{1,3 *}$ Oleg S. Koledin, ${ }^{1+}$ \\ Ella A. Kovaleva, ${ }^{2}$ and Svetlana A. Arslanbekova ${ }^{4}$ \\ ${ }^{1}$ Department of Oil and Gas Technology. Ufa State Petroleum Technical University. Cosmonauts St., 1. Ufa, \\ 450062. Republic of Bashkortostan. Russia. Phone: +7 (987) 606-47-91.E-mail: o.s.koledin@yandex.ru \\ ${ }^{2}$ Department of Mathematics. Ufa State Petroleum Technical University. Cosmonauts St., 1. Ufa, 450062. \\ Republic of Bashkortostan. Russia. Phone: +7 (917) 406-27-06.E-mail: kovaleva-ugntu@yandex.ru \\ ${ }^{3}$ Department of Physical Electronics and Nanophysics. Bashkir State University. Zaki-Validi St., 32. Ufa, \\ 450074. Republic of Bashkortostan. Russia.Phone: +7 (917) 429-44-63.E-mail:mdolomatov@bk.ru \\ ${ }^{4}$ Department of Mathematics. Bashkir State Agrarian University. 50th anniversary \\ of the October Revolution St., 34. Ufa, 450001. Republic of Bashkortostan. Russia. \\ Phone: +7 (917) 467-77-53. E-mail: s.arslanbeckova@yandex.ru
}

Keywords: alkanes; octane number; topological indices; eigenvalues of a topological matrix;

QSPR model.

\begin{abstract}
There may occur a special mode of combustion of the fuel-air mixture called detonation, when using motor fuel with a low octane rating.

Methods of mathematical modeling are currently used to quickly determine octane numbers without using of expensive equipment. A nonlinear multidimensional QSPR regression model is proposed to predict the octane number of normal and substituted alkanes-gasoline components.

The model associates octane numbers with a set of descriptors (topological characteristics of molecular graphs): the Randic index, the Wiener index, and the functions of the eigenvalues of the topological matrix of the molecule, reflecting the main structural and chemical factors, such as branching, the length of the carbon structure and the energy parameters of the molecules, for example perturbation of Hückel spectrum of molecules, as well as affecting octane numbers.

The substituted alkanes were used as research objects. A studied sample included 36 hydrocarbons from the homolologus serious of substituted alkanes. The proposed model adequately describes the octane number of alkanes. The coefficient of determination of the model is 0.972 . The model was tested on 19 substances which were not included in the base series. The average, absolute and relative error for the test sample of octane numbers were 1.5 units and $2.7 \%$ respectively.

The model is applicable for engineering and scientific forecasts of octane numbers of various alkanes in motor fuel.
\end{abstract}

\section{References}

[1] S.M. Frolov. Combustion Science and Problems of Contemporary Power Engineering. Russian Journal of General Chemistry. 2009. Vol.79. No.11. P.2556-2561. (russian)

[2] S.M. Frolov. Fast deflagration-to-detonation transition. Russian Journal of Physical Chemistry B. 2008. Vol.2. No.3. P.442-455

[3] V.E. Emelyanov, V.N.S kvortsov. Motor fuels: anti knock properties and Flammability. Moscow: Publishing house "Technology ", TUMA GROUP. 2006. 192p. (russian)

[4] A.B. Kopyl'tsova, B.P. Tarasov, O.V. Klim. Modern practice and problems when using industrial and laboratory spectrophotometer analyzers of the physicochemical properties of petroleum and petroleum products. Measurement Techniques. 2013. Vol.56. No.3. P.322-327. (russian)

[5] I. V. Stankevich, M. I. Stankevich, N.S. Zefirov. Topological indices in organic chemistry. Russ. Chem. Rev. 1988. Vol.57. No.3. P.337-366. (russian)

[6] V.G. Uryadov, N.V. Aristova, and E.N. Ofitserov. Numeric characteristic of the organic molecular structure. Part 10. Determination of numerical characteristics of normal alkanes by experimental data. Butlerov Communications. 2010. Vol.19. No.1. P.66-73. ROI: jbc-02/10-19-1-66 
[7] E.N. Ofitserov, Yu.V. Vlasenko, and V.G. Uryadov. Numerical characteristics of the structure of organic molecules. Part 15. Relationship of melting points of normal structure alkanes with the energy characteristics of molecules. Butlerov Communications. 2014. Vol.37. No.3. P.149-156. ROI: jbc-02/1437-3-149

[8] E.A. Smolenskii, G.V. Vlasova, and A.L. Lapidus. A study of the structure-octane number relationship for hydrocarbons. Doklady Physical Chemistry. 2004. Vol.397. Part 1. P.145-149.

[9] E.A. Smolenskii, A.N. Ryzhov, V.M. Bavykin, T.N. Myshenkova, A.L. Lapidus. Octane numbers (ONs) of hydrocarbons: a QSPR study using optimal topological indices for the topological equivalents of the ONs. Russian Chemical Bulletin. 2007. Vol.56. No.9. P.1681-1693.

[10] M.Yu. Dolomatov, T.M. Aubekerov. Relationship between Standard Enthalpies/Entropies of Formation and Topological Structural Characteristics for Saturated Hydrocarbons. Russian Journal of Physical Chemistry A. 2018. Vol.92. No.3. P.401-406. (russian)

[11] M.Yu. Dolomatov, T.M. Aubekerov, E.V. Vagapova, K.R. Akhtyamova, and E.A. Kuznetsov. Relationship of critical parameteres of liquid-vapour in phase transition and topological characteristics of aromatic hydrocarbons. Butlerov Communications. 2017. Vol.52. No.11. P.74-78. DOI: 10.37952/ROI-jbc-01/17-52-11-74

[12] M.Yu. Dolomatov, T.M. Aubekerov, E.V. Vagapova, and K.R. Akhtyamova. Topological approach to the calculation of the heat capacity of the ultimate hydrocarbons. Butlerov Communications. 2018. Vol.53. No.2. P.80-86. DOI: 10.37952/ROI-jbc-01/18-53-2-80

[13] M.J.S. Dewar, R.C. Dougherty. The PMO Theory of Organic Chemistry. Plenum Press. New York. 1975. $576 \mathrm{p}$.

[14] Swid. 201862459 Russian Federation. The Certificate on Official Registration of the Computer Database. Database of physical-chemical properties for organic compounds: M.Yu. Dolomatov, T.I. Pavlov, T.M. Aubekerov; the Applicant and Owner is Ufa State Petroleum Technological University (RU). No. 2017620709/69; Appl. 05.06.17; publ. 21.03.18. 